\title{
ASSESSMENT OF CORRELATION OF PREGNANCY PARAMETERS AND FETAL AGE FOR EWES
}

\author{
BAYAR K. ZEEBAREE \\ Dept. of Surgery And Internal Medicine, College of Veterinary Medicine, University of Duhok, \\ Kurdistan Region-Iraq.
}

(Received: July 31, 2021; Accepted for Publication: September 31, 2021)

\begin{abstract}
This study aimed to determine values of ewe's fetal developmental parameters and their correlations during pregnancy. The study carried out on eighteen variable parameters of 64 pregnant ewes collected from Duhok slaughterhouse. The average correlation of genital tract weight, crown to rump, head, thoracic, pelvic, orbital diameters, forelimbs, humerus, hind limb, Tibia, Occipito-nasal and greater length of skull were high $(>0.90)$. The umbilical cord circumferences, interorbital, fetal weight, and hoof length were moderately correlated $(>0.80)$ with other parameters. Potential hydrogen $(\mathbf{p H})$ of embryonic fluid had a negative correlation with other parameters. Fetal age, crown-rump length, thoracic, and fetal head diameters increased every 10 days. Genital tract weight, interorbital, and occipitonasal length increased every 20 to 30 days. However, length of skull was increased only during late pregnancy. The forelimb and hindlimb increased slightly with pregnancy development. Caruncle and umbilical cord diameters were increased during the half term of pregnancy then reduce or remain in the same diameters at the end. Embryonic fluid pH turns to acidity with fetal development. In conclusion, specific parameters are practical to confirm gestational age during specific gestational period when the date of breeding is unknown.
\end{abstract}

KEY WORDS: Gestational Stage, Embryo, Fetal Biometry, Correlation

\section{INTRODUCTION}

$\mathbf{P}$ regnancy diagnosis in sheep industry considered as an important method to improve sheep economic. Sheep offer milk, meat, and skin, also they are source of investment for most farmers in this region. The gestation length or date of natural service in most farm animals, particularly sheep flock are unknown. Therefore, reproducible pregnancy diagnosis method is critical in animal industry (Greenwood et al., 2002).

Diagnosis of pregnant ewe within flock and separation of pregnant animals from nonpregnant would bring a substantial benefit to the sheep industry and owner. Nonpregnant sheep can be managed to sell. However, pregnant ewe can receive intensive management, to reduce the incidence of abortion, stillbirth, dystocia as well as allowing to provide appropriate management, such as nutritional management to avoid metabolic diseases and pregnancy toxaemia. Furthermore, the prediction of fetal number, optimizing lamb weight, dry off lactation and monitoring ewe on late gestation stage or near lambing will be valuable (Doizé et al., 1997; Petrujkić et al., 2016; Shukran, 2015).

It is important to diagnose and estimate the gestation length of ewe, to manage and care the pregnant animals especially at late stage of pregnancy. Pregnant ewe may be sent to the slaughterhouse for economic reasons. Perhaps there are specific reason behind sending pregnant ewes for slaughter which is farmer not expecting that the sending ewes are pregnant.

Ultrasonography and ultrasound are an important technique and reliable method for pregnancy diagnoses in sheep (Doizé et al., 1997; García et al., 1993; Valasi et al., 2017). It is not possible to estimate the gestational age of unknown mating date without monitoring and measuring fetal growth. The most applied measurable parameters of foetal structure in the literatures are the length of crown to rump, diameter of fetal head, eye circumferences, thoracic, abdomen, skull, placental size, fetal weight, length of fore and hind limbs bone, heart rate of the fetus (Blankenvoorde, 2011; Shakir 
Khan et al., 2015; Zongo et al., 2018). It has been suggested that the correlation of the measurable parameters of fetal structure and the variation in nutrition and breed management for each breed should be considered during pregnancy diagnosis (Lawrence et al., 2016). Ultrasonographic scan has been improved without risk to pregnant animals, particularly through the abdominal and trans-rectal to visualised fetal development in term of pathological and physiological disorder (Shakir Khan et al., 2015).

There are several previous researches investigated the mechanisms for estimation of embryonic age (Correia Santos et al., 2018; Kuru et al., 2019; Shakir Khan et al., 2015), but information on local breed are limited. The fetal age cannot be predicted by ultrasonography without measuring fetal parameters. Furthermore, reliable data and correlation between pregnancy development and morphological characters of estimators for early and late gestation period in local sheep breed may not be achieved. Therefore, estimation of the pregnancy period by measuring biometry of local ewe fetus slaughtered at the abattoir will assist understanding and determining lambing periods. Identifying the correlation among fetus parameters for estimating fetal age by various anatomical growth are aimed to establish an accurate equation for determining the fetal age. Possibly, current research will be valuable for estimating the age of ewe fetus during various stage of pregnancy and concerning animal welfare aspect in term of estimating pregnancy stage.

\section{MATERIALS AND METHODS}

\subsection{Animals}

The genital tracts of pregnant ewe slaughtered during pregnancy season from September 2019 to March 2020. Sixty-four ewes were collected from slaughterhouse located in Duhok city, Kurdistan region of Iraq, $36.8632^{\circ}$ $\mathrm{N}, 42.9885^{\circ}$ E. All reproductive tracts were transported to local room in same abattoir and examined visually to determine uterine horn of pregnancy ewes.

\subsection{Verification of gravid uterus.}

The verification of the pregnant horn included the examination of the reproductive tracts through direct visual inspection and palpation based on; the greater curvature of uterine horn, persistent corpus luteum, asymmetry between uterine horn, palpation of embryonic fluid, caruncle and embryonic structure. Any abnormalities of reproductive system were excluded from study. After verification of pregnant uterus by direct visualization, the pregnant genital tracts were placed in plastic bags at abattoir and transported to the Theriogenology lab at college of Veterinary Medicine, Duhok University.

\subsection{Laboratory inspection}

The genital tracts of pregnant ewe were cleaned and removed from extra tissue, including vagina, then the weight of the reproductive tract was measured. After that the pregnant uteri incised to collect fetal fluid and measuring potential hydrogen $(\mathrm{pH})$ of fetal fluid. The uterine horn then dissected by incision made along the greater curvature of uterus and the measurable parameters of fetus were recorded

\subsection{Fetal parameters}

Fetus greater than $2 \mathrm{~cm}$ lengths were included for further investigation. The parameters including fetus weight, crown to anus length, head diameter, orbital diameter, interorbital diameter, Occipito-nasal diameter, greater length of skull, length of forelimb and hindlimb, humerus and tibia length, hoof diameter, pelvic diameter, umbilical cord diameters, and caruncle diameter of 58 pregnant ewes were documented for statistical analysis. The fetal measurements were made by digital balances, meter tape and calliper. The pregnant uteri in which embryo was unnoticeable by direct visualization and unable to measure parameters were excluded from assessment.

\subsection{Statistical analysis}

Statistical analyses were conducted to investigate the association among fetal parameters. In the first analysis, the correlation of measurable parameters (genital tract weighted, fetal fluid volume, $\mathrm{pH}$ of embryonic fluid, weight of fetus, crown to rump length, head diameter, orbital diameter, interorbital diameter, Occipito-nasal diameter, greater length skull, length of forelimb, length of hindlimb, humerus length, tibia length, pelvic diameter, umbilical cord diameters, caruncle diameter, hoof length) were analysed by correlation using GenStat software (GenStat $17^{\text {th }}$ edition, 2014). The correlation are categorized according to the strength of correlation into three groups; high correlation (>90), moderate correlation (80-90) and low correlation $(<80)$.

In the second analysis, fetometric parameters were grouped into 8 groups according to the equation $[(\mathrm{Y}=2.1(\mathrm{X}+17)$ where $\mathrm{Y}$ means age 
of fetus and $\mathrm{X}$ means the length of crown to anus in $\mathrm{cm}$ )] reported previously by (Noakes et al., 2018). Group I (aged 40 to 50 days; $\mathrm{N}=10$ ), Group II (aged 51 to 60 days; $N=12$ ), Group III (aged 61 to 70 days; $\mathrm{N}=6$ ), group IV (aged 71 to 80 days; $\mathrm{N}=5$ ), group $\mathrm{V}$ (aged 81 to 90 days; $\mathrm{N}=4$ ), group VI (aged 91 to 100 days; $\mathrm{N}=5$ ), Group VII (aged 101 to $110 ; \mathrm{N}=4$ ) and group VIII (aged 111 to $120 ; \mathrm{N}=7$ ). Animal in late stage of pregnancy were not sent to slaughter. The data were analysed by ANOVA using GenStat software. Least significant differences (LSD) were used as differences among means. The mean of different aged group within each parameter were compared and data are shown as mean with standard error of a difference between two means (SED).

\section{RESULTS}

Fetus from 64 ewes were obtained from local abattoir, 6 ewe genital tracts were excluded from study because incomplete information had been recorded as a results of small embryo and abnormal fetus. The average positive correlation among 58 ewes pregnancy parameters (Weight of genital tract, length from crown to rump, diameter of; head, thoracic, pelvic, orbital and length of; forelimbs, humerus, hind limb, tibia, Occipito-nasal and greater length of skull) were high $(>0.90)$. The circumferences of umbilical cord, interorbital, fetal weight, and hoof length were moderately correlated $(>0.80)$ with other parameters. There was a low correlation between the volume of embryonic fluid and other parameters, except correlation with forelimb were moderate. The diameters of caruncle had very low correlation with pregnancy parameters and all parameters had negative correlation (average negative correlation 0.77) with the potential hydrogen $(\mathrm{pH})$ of embryonic fluid.

The length of crown to rump and thoracic diameter had better correlation with most parameters (ranged from 0.85 to 0.98 ). Crown to rump length had strong correlation with thoracic diameter (0.98) and head diameters (0.97). However, crown rump length had weak correlation with embryonic fluid (0.75) and poorer correlation with caruncle diameters (0.24). Therefore, the age of fetus was determined according to crown rump length following the equation suggested by (Noakes et al., 2018). The correlation among pregnancy parameters for determination of ewe fetal age are shown in table 1.
In the second analysis, 18 parameters of fetus in pregnant ewes were grouped into 8 groups by 10 days period, according to crown rump length (Average correlation with other parameters was 0.93 and $\mathrm{R}^{2}=0.99$ within groups). The estimated coefficients of variation measurement and mean differences for embryo age were shown in Figures 1, 2, 3 and 4.

The general weight of genital tract became significantly heavier $\left(\mathrm{R}^{2}=0.82 ; \mathrm{P}>0.01\right.$; Fig. $\left.1 . \mathrm{A}\right)$ with every 20 days of fetal development. Fetal weight $\left(\mathrm{R}^{2}=0.83\right.$; $\mathrm{P}>0.01$; Fig.1.B $)$ and greater length of skull $\left(\mathrm{R}^{2}=0.92 ; \mathrm{P}>0.01\right.$; Fig.1.C) were nonsignificantly differ in early stage of pregnancy between groups (group I, II, III, IV), whereas significantly increased in late stage of pregnancy (V, VI, VII and VIII). The crown rump length had highest coefficient variant ( $\mathrm{R}$ ${ }^{2}=0.99 ; \quad \mathrm{P}>0.01 ; \quad$ Fig.1.D) followed by the diameters of thoracic $\left(R^{2}=0.96 ; P>0.01\right.$; Fig.1.E $)$ and fetal head $\left(R^{2}=0.94 ; P>0.01\right.$; Fig.1.F). These parameters increased gradually with increasing fetal age every 10 days. Fetal pelvic diameters $\left(\mathrm{R}^{2}=0.94\right.$; $\mathrm{P}>0.01$; Fig.2.A) were smaller in group I, compare to fetal at stage III and above. There was significant variation between group VIII and earlier stage of pregnancy in group VI. Orbital diameter increased during first four groups $\left(\mathrm{R}^{2}=0.92 ; \mathrm{P}>0.01 ;\right.$ Fig.2. $\left.\mathrm{B}\right)$, after that the circumference of eye did not change significantly. However, the interorbital diameters $\left(\mathrm{R}^{2}=0.79 ; \quad \mathrm{P}>0.01 ; \quad\right.$ Fig.2.C $)$ and occipitonasal length $\left(\mathrm{R}^{2}=0.91 ; \mathrm{P}>0.01 ;\right.$ Fig.2.D) increased during fetal development with every 20 to 30 days.

The comparatively high extent of forelimbs $\left(\mathrm{R}^{2}=0.92\right.$; $\mathrm{P}>0.01$; Fig.2.E) and hind limbs (R${ }^{2}=0.93$; P $>0.01$; Fig.2.F) length were faster at group VI. Similar observations were recorded for the fetal humerus-radius (Fig.3.A) and tibia bone (Fig.3.B). However, association of hoof length (Fig. 3.C) and embryonic fluid (Fig.3.D) with fetal age development were low. The diameters of caruncle increased during first trimester of pregnancy until reached greatest diameters in middle stage of pregnancy then reduced and flattened during late stage of pregnancy $\left(3.34 \mathrm{~cm} ; \mathrm{R}^{2}=0.43 ; \mathrm{P}<0.01\right.$; Fig. 3.E). The diameters of umbilical cord were increased till group VI and remain in the same diameters $\left(\mathrm{R}^{2}=0.72 ; \mathrm{P}>0.01\right.$; Fig.3.F $)$. However, the $\mathrm{pH}$ measurements were reduced and turned (R${ }^{2}=0.62$; P $>0.01$; Fig. 4.A) to acidity with fetal age 
Table (1): The correlation among sheep fetus parameters in local ewes slaughtered at a local abattoir in Duhok region.

\begin{tabular}{|c|c|c|c|c|c|c|c|c|c|c|c|c|c|c|c|c|c|c|c|}
\hline Parameters Correlatior & & G W & C R & F W & F H D & T D & $\mathbf{P}$ & H L & Fo L & TB & Hi L & O D & 10 & os & G L S & $\mathbf{H}$ & UCD & EF & $\mathrm{pH}$ \\
\hline Genital weight (gm) & G W & & 0.91 & 0.95 & 0.91 & 0.95 & 0.89 & 0.89 & 0.96 & 0.91 & 0.95 & 0.89 & 0.87 & 0.92 & 0.93 & 0.88 & 0.81 & 0.75 & 0.77 \\
\hline Crown-Rump (cm) & C R & 0.91 & & 0.86 & 0.97 & 0.98 & 0.96 & 0.97 & 0.97 & 0.95 & 0.97 & 0.94 & 0.88 & 0.96 & 0.95 & 0.89 & 0.85 & 0.73 & 0.77 \\
\hline Fetal weight (gm) & F W & 0.95 & 0.86 & & 0.84 & 0.91 & 0.85 & 0.83 & 0.93 & 0.91 & 0.92 & 0.78 & 0.80 & 0.89 & 0.89 & 0.89 & 0.75 & 0.66 & 0.80 \\
\hline Fetal head diameter $(\mathrm{cm})$ & F H D & 0.91 & 0.97 & 0.84 & & 0.96 & 0.95 & 0.94 & 0.94 & 0.92 & 0.95 & 0.94 & 0.88 & 0.93 & 0.93 & 0.83 & 0.84 & 0.73 & 0.77 \\
\hline Thoracic diameter $(\mathrm{cm})$ & T D & 0.95 & 0.98 & 0.91 & 0.96 & & 0.96 & 0.95 & 0.98 & 0.95 & 0.98 & 0.94 & 0.89 & 0.97 & 0.97 & 0.92 & 0.88 & 0.73 & 0.77 \\
\hline Pelvic & $\mathbf{P}$ & 0.89 & 0.96 & 0.85 & 0.95 & 0.96 & & 0.93 & 0.93 & 0.93 & 0.95 & 0.92 & 0.92 & 0.93 & 0.93 & 0.87 & 0.87 & 0.71 & 0.76 \\
\hline Humerus length $(\mathrm{cm})$ & H L & 0.89 & 0.97 & 0.83 & 0.94 & 0.95 & 0.93 & & 0.96 & 0.98 & 0.95 & 0.91 & 0.83 & 0.91 & 0.94 & 0.85 & 0.80 & 0.88 & 0.72 \\
\hline Fore $\operatorname{limb}(\mathrm{cm})$ & Fo L & 0.96 & 0.97 & 0.93 & 0.94 & 0.98 & 0.93 & 0.96 & & 0.98 & 0.99 & 0.93 & 0.87 & 0.96 & 0.97 & 0.92 & 0.85 & 0.86 & 0.80 \\
\hline Tibia length $(\mathrm{cm})$ & TB & 0.91 & 0.95 & 0.91 & 0.92 & 0.95 & 0.93 & 0.98 & 0.98 & & 0.98 & 0.89 & 0.82 & 0.93 & 0.94 & 0.90 & 0.79 & 0.74 & 0.76 \\
\hline Hind $\operatorname{limb}(\mathrm{cm})$ & Hi L & 0.95 & 0.97 & 0.92 & 0.95 & 0.98 & 0.95 & 0.95 & 0.99 & 0.98 & & 0.92 & 0.87 & 0.96 & 0.95 & 0.92 & 0.83 & 0.77 & 0.80 \\
\hline Orbit diameter $(\mathrm{cm})$ & O D & 0.89 & 0.94 & 0.78 & 0.94 & 0.94 & 0.92 & 0.91 & 0.93 & 0.89 & 0.92 & & 0.91 & 0.91 & 0.90 & 0.85 & 0.85 & 0.74 & 0.77 \\
\hline Interorbital (cm) & 10 & 0.87 & 0.88 & 0.80 & 0.88 & 0.89 & 0.92 & 0.83 & 0.87 & 0.82 & 0.87 & 0.91 & & 0.89 & 0.83 & 0.79 & 0.78 & 0.69 & 0.69 \\
\hline Occipito-nasal (cm) & os & 0.92 & 0.96 & 0.89 & 0.93 & 0.97 & 0.93 & 0.91 & 0.96 & 0.93 & 0.96 & 0.91 & 0.89 & & 0.96 & 0.85 & 0.88 & 0.68 & 0.76 \\
\hline Greatest skull length $(\mathrm{cm})$ & G LS & 0.93 & 0.95 & 0.89 & 0.93 & 0.97 & 0.93 & 0.94 & 0.97 & 0.94 & 0.95 & 0.90 & 0.83 & 0.96 & & 0.92 & 0.85 & 0.76 & 0.80 \\
\hline Hoof $(\mathrm{cm})$ & $\mathbf{H}$ & 0.88 & 0.89 & 0.89 & 0.83 & 0.92 & 0.87 & 0.85 & 0.92 & 0.90 & 0.92 & 0.85 & 0.79 & 0.85 & 0.92 & & 0.72 & 0.79 & 0.78 \\
\hline Umbilical cord diameter & UCD & 0.81 & 0.85 & 0.75 & 0.84 & 0.88 & 0.87 & 0.80 & 0.85 & 0.79 & 0.83 & 0.85 & 0.78 & 0.88 & 0.85 & 0.72 & & 0.63 & 0.73 \\
\hline Average correlation & $A V$ & 0.91 & 0.93 & 0.87 & 0.91 & 0.95 & 0.92 & 0.91 & 0.94 & 0.92 & 0.94 & 0.90 & 0.86 & 0.92 & 0.92 & 0.87 & 0.82 & 0.74 & 0.77 \\
\hline Embryonic fluid (ml) & E F & 0.75 & 0.73 & 0.66 & 0.73 & 0.73 & 0.71 & 0.88 & 0.86 & 0.74 & 0.77 & 0.74 & 0.69 & 0.68 & 0.76 & 0.79 & 0.63 & & 0.68 \\
\hline pH Negative correlation & $\mathrm{pH}$ & 0.77 & 0.77 & 0.80 & 0.77 & 0.77 & 0.76 & 0.72 & 0.80 & 0.76 & 0.80 & 0.77 & 0.69 & 0.76 & 0.80 & 0.78 & 0.73 & 0.68 & \\
\hline Caruncle diameter & CD & 0.22 & 0.24 & 0.06 & 0.09 & 0.19 & 0.23 & 0.08 & 0.08 & 0.12 & 0.07 & 0.34 & 0.30 & 0.28 & 0.20 & 0.2 & 0.02 & 0.18 & 0.19 \\
\hline
\end{tabular}

The average correlation shown in table excluded embryonic fluid, caruncle diameters and $\mathrm{pH}$ correlation. 
A

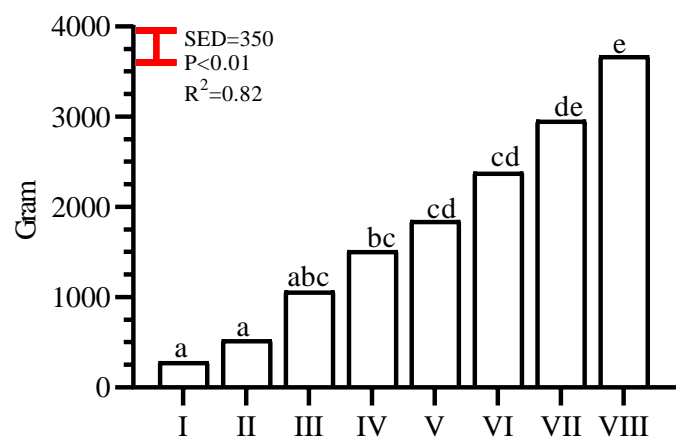

Stage of pregnancy development

C

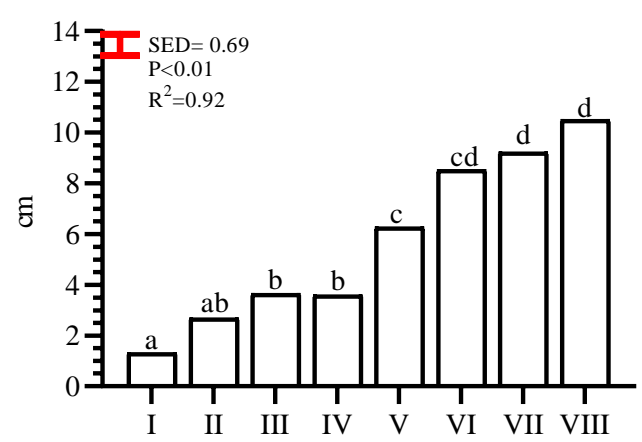

Stage of pregnancy development

$\mathbf{E}$

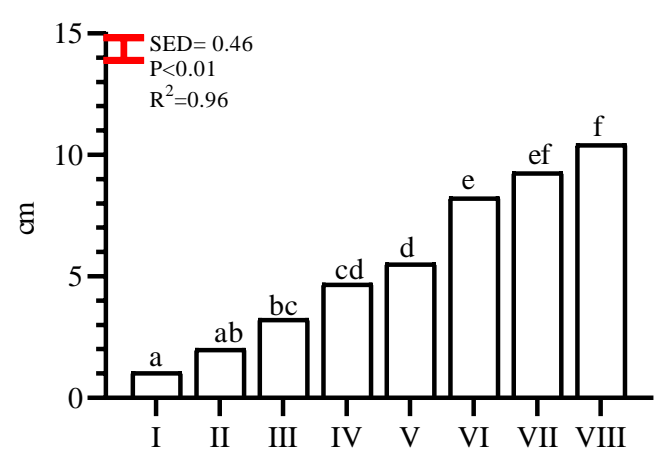

Stage of pregnancy development

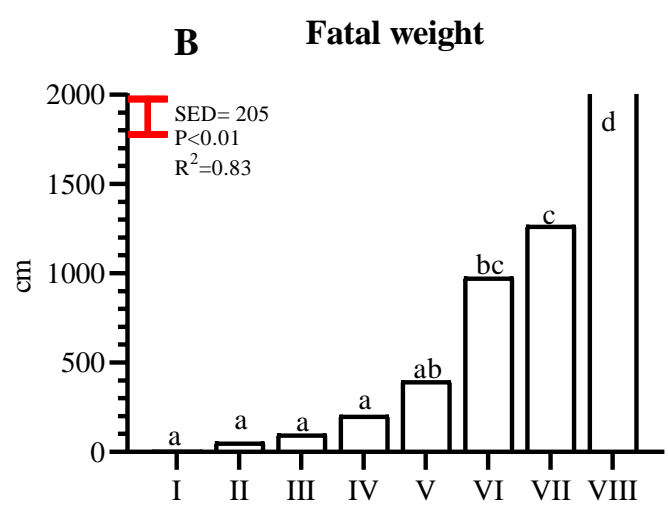

Stage of pregnancy development

\section{Crown rump length}

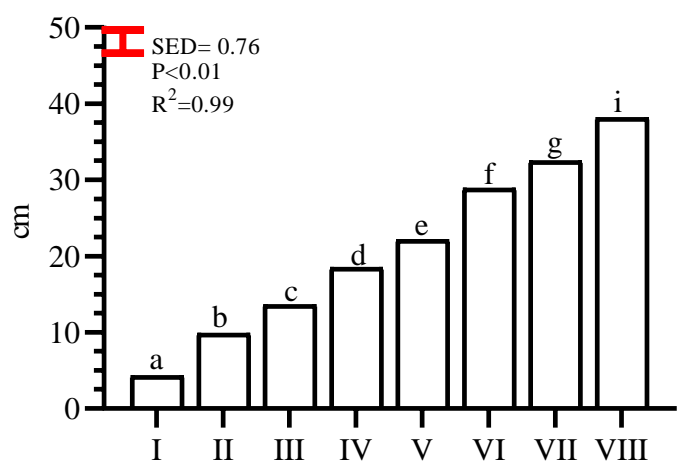

Stage of pregnancy development

\section{F Fetal head diameters}

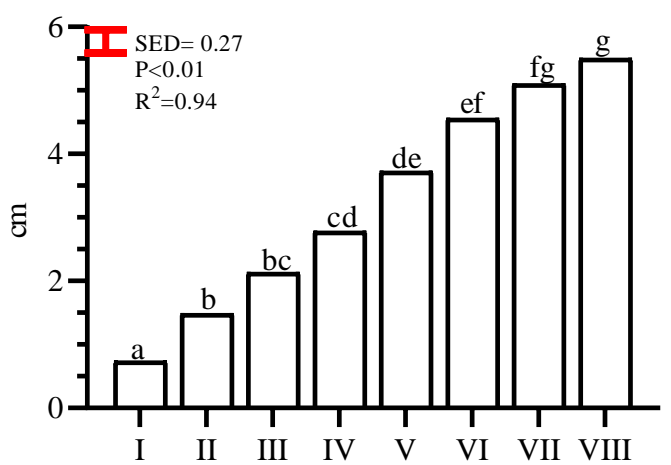

Stage of pregnancy development

Fig. (1): Trend relationship of A. Genital tract weight (gm), B. Fetal weight (gm), C. Skull length (cm), D. Crown to rump length $(\mathrm{cm})$, E. Thoracic diameters $(\mathrm{cm})$ and $\mathrm{F}$. Head diameter $(\mathrm{cm})$ at corresponding gestational stage. Variable were evaluated by crown to rump length according to [age $=2.1$ (crown to rump $(\mathrm{cm})+17)$ ] equation. Data are presented as mean with SED and LSD used to estimate significant differences between mean. Superscripts letters highlight differences between stags. 
A

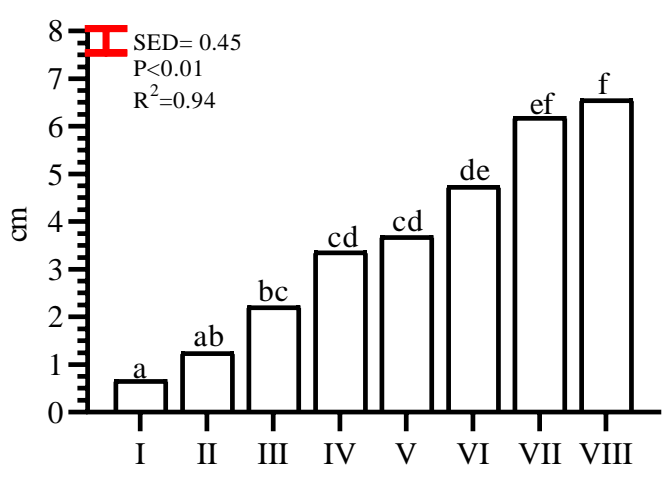

Stage of pregnancy development

$\mathbf{C}$

Interorbital diameters

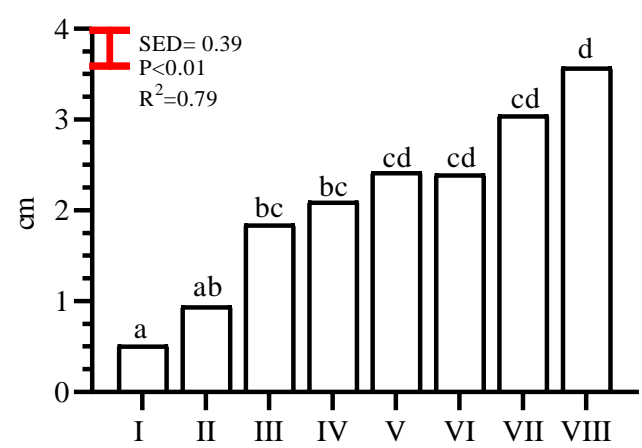

Stage of pregnancy development

$\mathbf{E}$

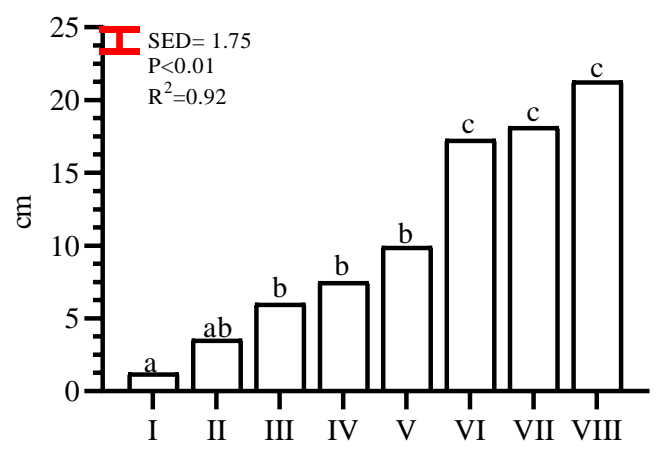

Stage of pregnancy development
B

Orbit diameters

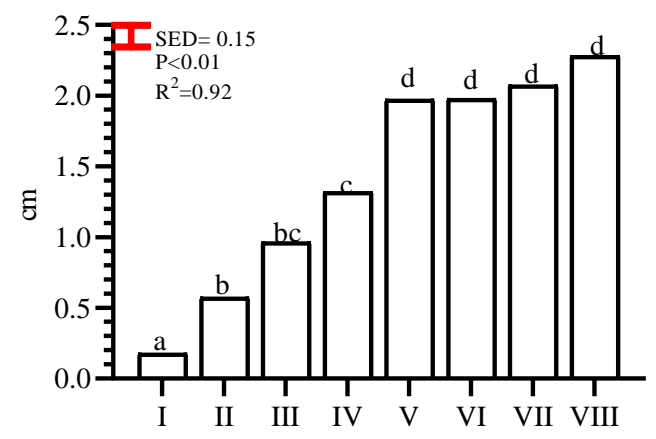

Stage of pregnancy development

D Occipito nasal length

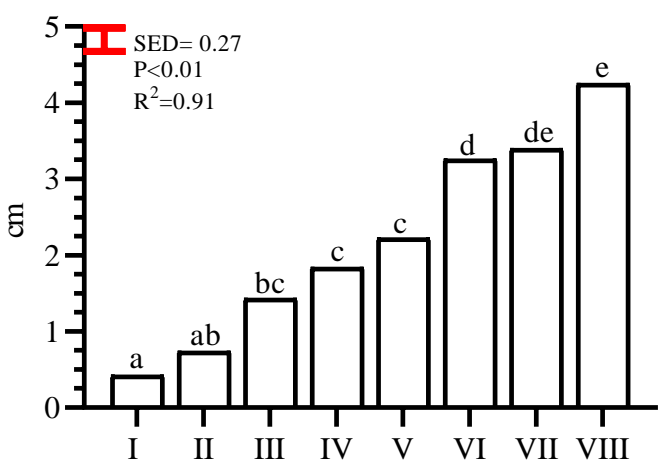

Stage of pregnancy development

F Hindlimb lentgh

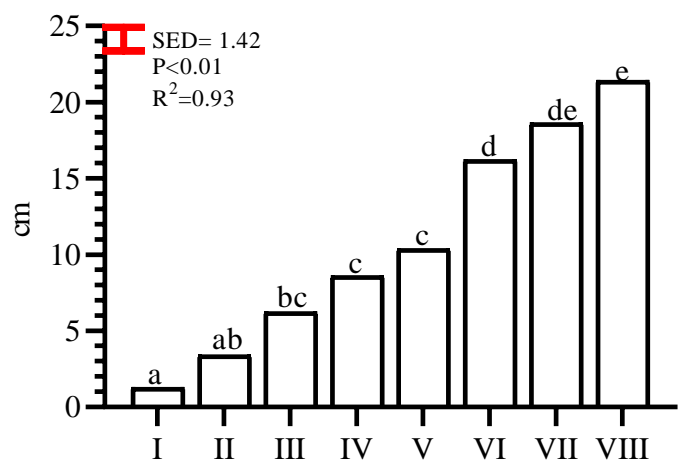

Stage of pregnancy development

Fig. (2): Trend relationship of A. Pelvic diameter $(\mathrm{cm})$, B. Orbital diameter $(\mathrm{cm})$, C. Inter orbital diameter $(\mathrm{cm})$, D. Occipitonasal length $(\mathrm{cm})$, E. Forelimb $(\mathrm{cm})$ and F. Hindlimb length $(\mathrm{cm})$ at corresponding gestational stage. Variable were evaluated by crown to rump length according to [age $=2.1$ (crown to rump $(\mathrm{cm})+17)$ ] equation.

Data are presented as mean with SED and LSD used to estimate significant differences between mean. Superscripts letters highlight differences between stags. 


\section{Humerus redius length}

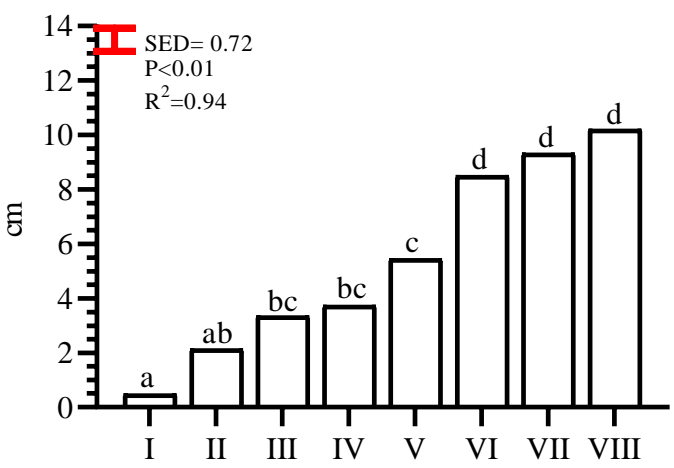

Stage of pregnancy development

Hoof length

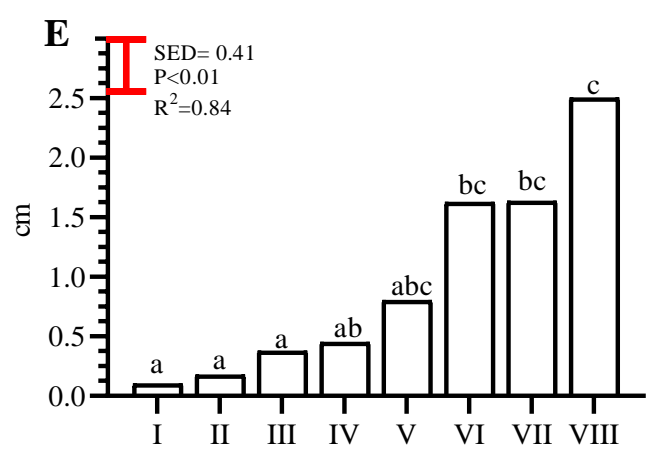

Stage of pregnancy development

\section{Caruncle diameters}

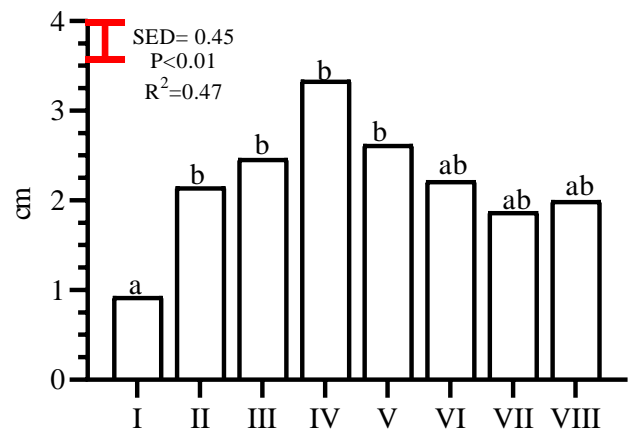

Stage of pregnancy development
D

Tibia length

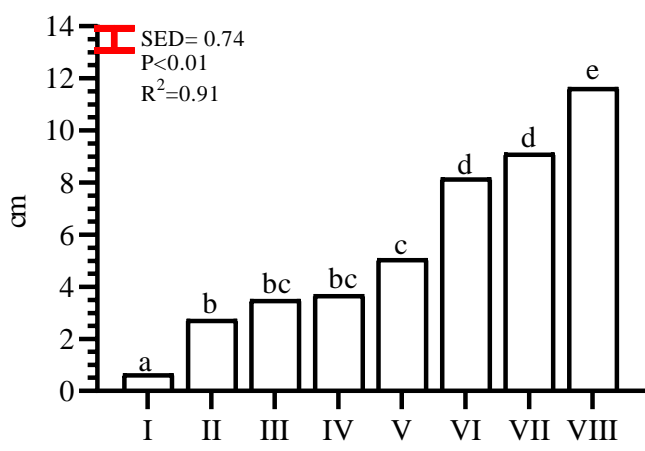

Stage of pregnancy development

Fatal fluid

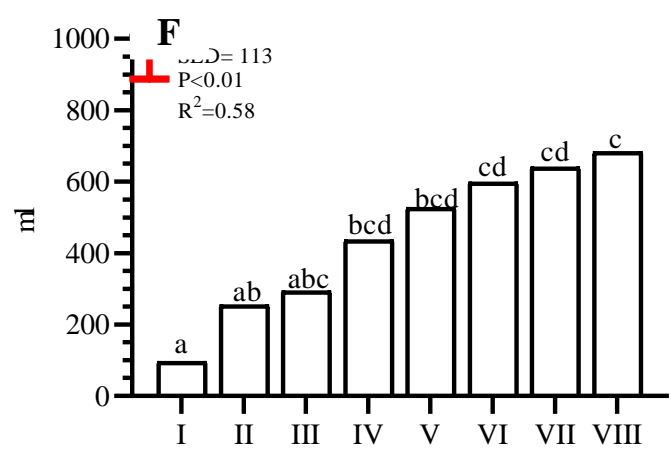

Stage of pregnancy development

Umbilical cord diameter

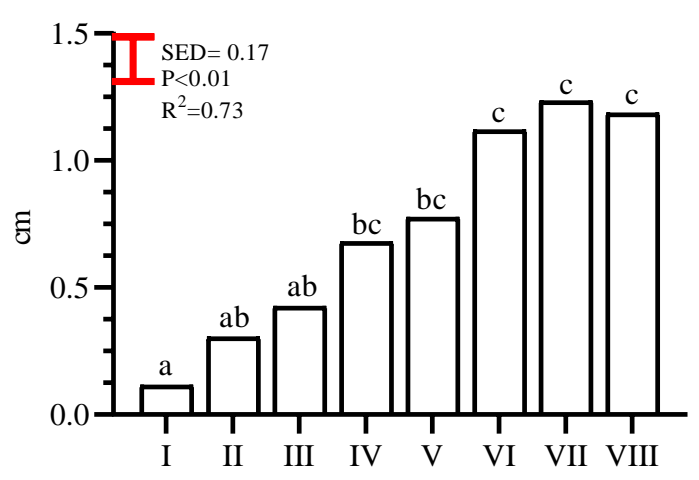

Stage of pregnancy development

Fig. (2): Trend relationship of A. Humerus radius length $(\mathrm{cm})$, B. Tibia length $(\mathrm{cm})$, C. Hoof length $(\mathrm{cm})$, D. Fetal fluid $(\mathrm{mm})$, E. Caruncle diameter $(\mathrm{cm})$ and F. Umbilical cord diameters $(\mathrm{cm})$ at corresponding gestational stage. Variable were evaluated by crown to rump length according to [age $=2.1$ (crown to rump $(\mathrm{cm})+17)$ ] equation. Data are presented as mean with SED and LSD used to estimate significant differences between mean. Superscripts letters highlight differences between stags. 
A

pH

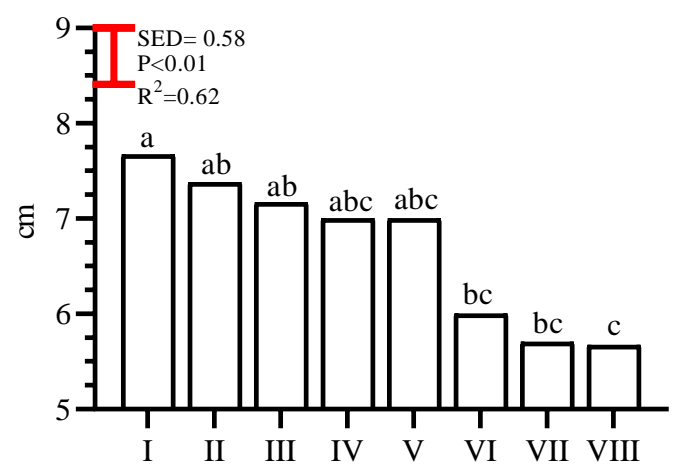

Stage of pregnancy development

Fig. (4): Trend relationship of acidity of fetal fluid $(\mathrm{pH})$ at corresponding gestational stage. Variable were evaluated by crown to rump length according to [age $=2.1$ (crown to rump $(\mathrm{cm})+17)$ ] equation. Data are presented as mean with SED and LSD used to estimate significant differences between mean. Superscripts letters

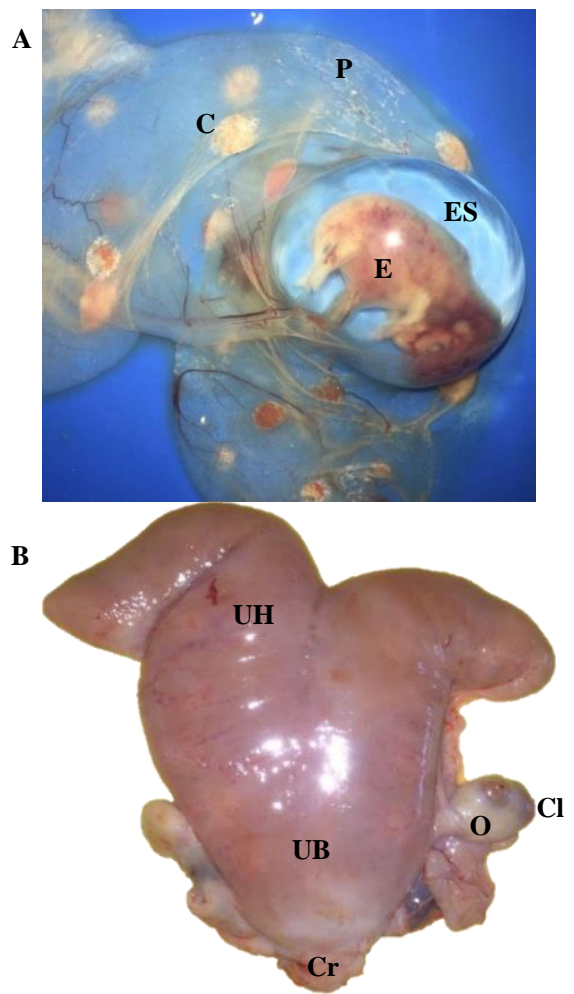
highlight differences between stags.

Fig. (5): Show genital tract of pregnant ewe at different stage of gestation. Early stage of embryo development within the ewe uterus carrying single or multiple fetus (A). Complete genital tract collected from slaughter house revealed enlarged uterus filled with embryo fluid, uterine caruncle and corpus luteum on ovary (B). Caruncle (C), placenta (P), embryo (E), embryonic sac (ES), uterine horn (UH), uterine body (UB), ovary (O), corpus luteum $(\mathrm{CL})$ and closed cervix $(\mathrm{Cr})$. 


\section{DISCUSSION}

The previous fetal measurement studies have not been adequately covered and compared all parameters related to determine fetal age. In this study, most parameters related to pregnancy development have been identified. These parameters will be establishing a useful basis for providing a formula to calculate fetal age. The fetometric variables of ewe fetus in this study consist of genital tract weight, crown to rump length, volume of fetal fluid, fetus weight, head diameter, orbital diameter, interorbital diameter, thoracic diameter, occipitonasal length, greater length skull, length of forelimb and hindlimb, humerus radius and tibia length, hoof length, pelvic diameter, umbilical cord diameters, caruncle diameter and $\mathrm{pH}$ of fetal fluid. The measurement of eighteen parameters combined to provide a good prediction of ewe fetal age. The authority of veterinary are in great necessity of scientifically presented data for estimating fetal age (Krog et al., 2018). Care should be taken during pregnancy development, especially during early pregnancy and towered parturition.

The pregnancy parameters presented in this study are more reliable and objective as they increase over the entire period of gestation. The diameter of caruncles, fetal head, orbital diameter and length of tibia exerted great variation during early pregnancy. However, there were no variation of caruncles diameter, forelimb bones length, orbital circumference, umbilical cord diameters, fetal fluid and length of skull. In addition, the parameters estimation during the late pregnancy exerted great variation include weight of both genital tract and fetus, length of hindlimb bone, occipitonasal and hoof. Furthermore, crown to rump length, thoracic diameters and fetal head varied every 10 to 20 days of fetal development during pregnancy period.

Estimation of parameters for local sheep breed are required, because there was significant variation in quantitative parameters among the fetometric variables of different breed (Swett et al., 1948). The present study focused on estimators of the local ewe breed which can provide scientific data to expect gestation period. Caruncle diameters had weakest correlation with other parameters and no linear regression with gestational age. The diameter of caruncles in sheep and goat monitored throughout pregnancy period using transabdominal scan had no significant correlation with gestation age. The study reported that the caruncle diameters was not useful to estimate age of fetus in late pregnancy, whereas it was beneficial in mid gestation (Waziri et al., 2017). Additionally, the umbilical cord was diagnosed during early pregnancy in sheep and the diameters increased during the first three months of gestation then remain in the same diameter (AL-Salman et al., 2007). The average correlations of umbilical cord (0.82) and caruncle diameters (0.15) with other parameters were moderate and poor respectively. The poor correlation between placentome size, diameters and gestational age were recorded by (Doizé et al., 1997; Nwaogu et al., 2010) in sheep and goat, respectively. The highest correlations in the current study were recorded among crown to rump length, head diameters and thoracic diameters. It has been estimated that gestation age in sheep had batter correlation with crown to rump, bi-parietal diameter, occipito-snout length, thoracic and head circumferences (Santiago-Moreno et al., 2005; Shakir Khan et al., 2015). Best correlation among head diameters, trunk diameters and crown to rump length with gestational age were obtained in a study conducted on goat by (Kuru et al., 2019).

The length of femur in cattle had moderate correlation $\left(\mathrm{R}^{2}=0.64\right)$ with gestation age (Bunyaga, 2017). However, in sheep femur bone continue to grow until lambing, while humerus length significantly increased between 106 and 120 days and remain at same size onward (Vannucchi et al., 2019). Similar observations were recorded in the current study, humerus and forelimb lengths significantly increased in mid gestation and remain unaltered in late stage of pregnancy, whereas tibia and hind limbs, increased in the last gestational group. According to Correia Santos et al, the length of forelimb bone, scapula and humerus, are not easy to asses and are less relevant to estimate gestation age (Correia Santos et al., 2018). Pelvic diameter increased every 20 days of pregnancy and had a better correlation with gestational period and the average correlation with other parameters was greater than $\left(\mathrm{R}^{2}<0.90\right)$. Interischial distance measurement had strong correlation with gestational age in pregnant women using ultrasonography (AlEsawi et al., 2016). The $\mathrm{pH}$ of fetal fluid was reduced steadily and there was a negative correlation between $\mathrm{pH}$ in fluid and other 
parameters. Previous study showed that the $\mathrm{pH}$ in amniotic fluid reduced with increased gestational age in human (Seeds et al., 1968) and it affected by both fetal and maternal state (Semerci et al., 2016).

In conclusion, current study offered a validated estimator for ewe gestational period depends on variables. Variables consist of combination of eighteen fetometric parameters which may provide a better prediction of fetal age of the sheep. Possibly, these parameters can develop a useful model that can be used to predict accurate gestational period. High correlation between specific pregnancy parameters during early or late gestation stage could express mathematical equation concerning pregnancy period in ewes

\section{Acknowledgments}

Author wish to thank College of Veterinary Medicine at Duhok University and Director of Veterinary in Duhok province for providing facilities and supporting

\section{REFERENCES}

Al-Esawi, S. R., Al-Hashimi, N. M., Ali, F., \& Hussain, S. (2016). Gestational age estimation based on fetal pelvimetry on fetal ultrasound in Iraqi Women. Journal of Global Radiology, 2(1). doi: 10.7191/jgr.2016.1027

AL-Salman, M. H., M. AL-Rawi, H., \& N. Omran, S. (2007). Estimation of fetal age in sheep by measurement of the embryonic vesicle diameter and umbilical cord diameter by using real-time ultrasonography. Iraqi Journal of Veterinary Sciences, 21(1), 159-167. doi: 10.33899/ijvs.2007.5638

Blankenvoorde, G. H. H. (2011). Determination of gestational age in dairy cattle using transrectal ultrasound measurements of placentome size. In University Utrecht Repository.

Bunyaga, A. (2017). The use of fetal femur length for estimation of gestational age in cattle. Tanzania Veterinary Journal, 35(1), 244-249.

Correia Santos, V. J., Garcia Kako Rodriguez, M., del Aguila da Silva, P., Sitta Gomes Mariano, R., Taira, A. R., de Almeida, V. T., Ramirez Uscategui, R. A., Nociti, R. P., Maia Teixeira, P. P., Rossi Feliciano, M. A., \& Russiano Vicente, W. R. (2018). B-mode ultrasonography and ecobiometric parameters for assessment of embryonic and fetal development in sheep. Animal Reproduction Science, 197, 193-202. doi: 10.1016/j.anireprosci.2018.08.028

Doizé, F., Vaillancourt, D., Carabin, H., \& Bélanger,
D. (1997). Determination of gestational age in sheep and goats using transrectal ultrasonographic measurement of placentomes. Theriogenology, 48(3), 449-460. doi: 10.1016/S0093-691X(97)00254-9

García, A., Neary, M. K., Kelly, G. R., \& Pierson, R. A. (1993). Accuracy of ultrasonography in early pregnancy diagnosis in the ewe. Theriogenology, 39(4), 847-861. doi: 10.1016/0093-691X(93)90423-3

Greenwood, P. L., Slepetis, R. M., McPhee, M. J., \& Bell, A. W. (2002). Prediction of stage of pregnancy in prolific sheep using ultrasound measurement of fetal bones. Reproduction, Fertility and Development, 14(1-2), 7-13. doi: 10.1071/RD01047

Krog, C. H., Agerholm, J. S., \& Nielsen, S. S. (2018). Fetal age assessment for Holstein cattle. PLoS ONE, 13(11). doi: 10.1371/journal.pone.0207682

Kuru, M., Oral, H., \& Kulaksiz, R. (2019). Determination of gestational age by measuring defined embryonic and foetal indices with ultrasonography in abaza and gurcu goats. Acta Veterinaria Brno, 87(4), 357-362. doi: 10.2754/avb201887040357

Lawrence, K. E., Adeyinka, F. D., Laven, R. A., \& Jones, G. (2016). Assessment of the accuracy of estimation of gestational age in cattle from placentome size using inverse regression. New Zealand Veterinary Journal, 64(4), 248-252. doi: 10.1080/00480169.2016.1157050

Noakes, D. E., Parkinson, T. J., \& England, G. C. W. (2018). Veterinary reproduction and obstetrics. In Veterinary Reproduction \& Obstetrics. Saunders. doi: 10.1016/C2014-0-04782-X

Nwaogu, I. C., Anya, K. O., \& Agada, P. C. (2010). Estimation of foetal age using ultrasonic measurements of different foetal parameters in red Sokoto goats (Capra hircus). Veterinarski Arhiv, 80(2), 225-233.

Petrujkić, B. T., Cojkić, A., Petrujkić, K., Jeremić, I., Mašulović, D., Dimitrijević, V., Savić, M., Pešić, M., \& Beier, R. C. (2016). Transabdominal and transrectal ultrasonography of fetuses in Württemberg ewes: Correlation with gestational age. Animal Science Journal, 87(2), 197-201. doi: 10.1111/asj.12421

Santiago-Moreno, J., González-Bulnes, A., GómezBrunet, A., Toledano-Díaz, A., \& LópezSebastián, A. (2005). Prediction of gestational age by transrectal ultrasonographic measurements in the mouflon (ovis gmelini musimon). Journal of Zoo and Wildlife Medicine, 36(3), 457-462. doi: 10.1638/04107.1

Seeds, A. E., \& Hellegers, A. E. (1968). Acid-base 
determinations in human amniotic fluid throughout pregnancy. American Journal of Obstetrics and Gynecology, 101(2), 257-260. doi: 10.1016/0002-9378(68)90196-8

Semerci, S. Y., Yucel, B., Erbas, I. M., Gunkaya, O. S., Talmac, M., Babayigit, A., Cebeci, B., Buyukkale, G., \& Cetinkaya, M. (2016). The predictive value of amniotic fluid ph and electrolytes on neonatal respiratory disorders. Journal of Maternal-Fetal and Neonatal Medicine, 29, 45.

Shakir Khan, M., Ahmad, S., Ahmad Swati, Z., Akhtar, S., Rahman, A., Ahmad, S., Swati, Z., Akhtar, S., \& Rahman, A. (2015). Gestational age estimation in Kari sheep at different gestational length using trans-abdominal ultrasonographic fetometry. Journal of Anim. Health \&Produc, 23(1), 9-19.

Shukran, A. (2015). Estimation of gestational age by the use of fetal parameters: placentome, femur length, and biparietal diameter. Massey University.

Swett, W., Fohrman, M., \& Matthews, C. (1948). Development of the Fetus in the Dairy Cow. US Department of Agriculture, Technical Bulletin No 964, 34.
Valasi, I., Barbagianni, M. S., Ioannidi, K. S., Vasileiou, N. G. C., Fthenakis, G. C., \& Pourlis, A. (2017). Developmental anatomy of sheep embryos, as assessed by means of ultrasonographic evaluation. Small Ruminant Research, 152, 56-73. doi: 10.1016/j.smallrumres.2016.12.016

Vannucchi, C. I., Veiga, G. A. L., Silva, L. C. G., \& Lúcio, C. F. (2019). Relationship between fetal biometric assessment by ultrasonography and neonatal lamb vitality, birth weight and growth. Animal Reproduction, 16(4), 923-929. doi: 10.21451/1984-3143-AR2019-0006

Waziri, M. A., Ikpe, A. B., Bukar, M. M., \& Ribadu, A. Y. (2017). Determination of gestational age through trans-abdominal scan of placentome diameter in Nigerian breed of sheep and goats. Sokoto Journal of Veterinary Sciences, 15(2), 49. doi: 10.4314/sokjvs.v15i2.7

Zongo, M., Kimsé, M., Essozimna Abalo, K., \& Sanou, D. (2018). Fetal growth monitoring using ultrasonographic assessment of femur and tibia in Sahelian goats. In Journal of Animal \&Plant Sciences (Vol. 36). 